\title{
ETIKA PERAWAT DALAM PENERAPAN KEBIJAKAN K3RS
}

\section{NURAINI SIHITE}

\section{Email : nurainisihite@gmail.com}

\section{Latar belakang}

Perawat adalah tenaga kesehatan yang paling besar jumlahnya dan paling lama kontak dengan pasien, sehingga sangat berisiko dengan pekerjaannya, namun banyak perawat tidak menyadari terhadap risiko yang mengancam dirinya, melupakan keselamatan dan kesehatan kerja (K3).

Rumah sakit yang merupakan institusi pelayanan kesehatan yang menyelenggarakan pelayanan kesehatan perorangan secara Paripurna yang meliputi rawat jalan, rawat inap, laboratorium, dan gawat darurat. Rumah sakit termasuk tempat kerja dengan berbagai potensi bahaya yang dapat menimbulkan dampak ataupun resiko terhadap keselamatan dan kesehatan kerja. Resiko ini tidak hanya terhadap para pelaku langsung yang bekerja di rumah sakit, namun juga terhadap pasien, pengunjung dan masyarakat yang berada di sekitar lingkungan rumah sakit.

Keberhasilan program Kesehatan dan Keselamatan Kerja (K3) di rumah sakit tidak lepas dari sikap kepatuhan personal baik dari pihak perawat maupun pihak manajemen atas dalam melaksanaan peraturan dan kebijakan peraturan K3 untuk mendukung pencapaian zero accident di rumah sakit.

Dalam melaksanakan setiap Program Keselamatan dan Kesehatan Kerja tersebut, para pekerja rumah sakit mempunyai resiko untuk terjadinya Penyakit Akibat Kerja (PAK) dan Kecelakaan Akibat Kerja (KAK). Hal ini disebabkan karena Penyakit Akibat Kerja (PAK) merupakan penyakit yang disebabkan oleh pekerjaan, alat kerja, bahan, proses maupun lingkungan kerja.

Penyakit Akibat Kerja (PAK) di rumah sakit dapat menyerang semua tenaga kerja, baik medis (perawat, dan dokter), maupun non medis (petugas kebersihan (cleaning service)) mempunyai resiko untuk terpajan bahan biologi berbahaya (biohazard), dan kontak dengan alat medis sekali pakai (disposable aquipment) seperti jarum suntik bekas maupun selang infus bekas, serta membersihkan seluruh ruangan di rumah sakit dapat meningkatkan resiko untuk terkena penyakit infeksi bagi petugas kebersihan (cleaning service) rumah 
sakit.3Rumah Sakit Umum Daerah Kota Semarang merupakan rumah sakit rujukan di Kota Semarang yang memiliki tugas dan fungsi sebagai tempat pelayanan kesehatan, yang memiliki potensi terjadinya penyakit akibat kerja dan kecelakaan akibat kerja yang dialami oleh petugas kesehatan, pasien maupun pengunjung rumah sakit..

Manajemen risiko k3 RS wajib dilaksanakan secara menyeluruh di rumah sakit, karena kegiatan manajemen resiko bertujuan untuk meminimalkan risiko keselamatan dan kesehatan di rumah sakit sehingga tidak menimbulkan efek buruk terhadap keselamatan dan kesehatan SDM Rumah Sakit, pasien, pendamping pasien atau keluarga, dan pengunjung.

\section{Metode}

Metode yang digunakan pada kajian ini adalah metode kualitatif yang memberikan penjelasan dengan menggunakan analisis pada referensi yang digunakan. Untuk mengumpulkan data-data dari beberapa jurnal dan e-book dari situs internet yang berhubungan dengan topik pembahasan yaitu etika perawat dalam penerapan kebijakan K3RS. Karena keterbatasan waktu, cakupan luas dari topik, dan untuk lebih spesifik, maka dilakukan batasan waktu pada tahun publikasinya dengan waktu minimalnya delapan tahun terakhir yaitu dari tahun 2012 dengan mengambil referensi yang terkait dengan topik yang digunakan.

\section{Hasil}

Kebijakan K3 merupakan syarat penting penerapan sistem menageman kesehatan dan keselamatan kerja atau SMK3 di organisasi. Kebijakan K3 adalah komitmen manajemen terhadap K3 dalam bentuk nyata tertuang tertulis yang memuat pokok kebijakan perusahaan terkait penerapan K3dalam organisasi (Ramli, 2013).

Menurut Bloom (1975) dalam Notoatmodjo (2007), pengetahuan merupakan pemberian bukti seseorang dari proses pengingatan atau pengenalan informasi dan ide yang sudah diperoleh sebelumnya. Kebijakan K3 yang dibuat oleh RS dapat digunakan untuk meningkatkan pengetahuan respondenmeskipun dalam hal ini bukan faktor penyebab pengetahuan meningkat. Kebijakan K3 secara tertulis untuk menuangkan kebijakan RS tentang pelaksanaan K3 dalam organisasi.Kebijakan K3 secara tertulis untuk memberikan informasi kepada pekerja RS, yang mengunjungi RS, dan pihak yang bekerja sama dengan RS terkait kebijakan K3 yang berlaku di RS. 
Keberadaan tenaga kerja bidang K3 di RS dan tenaga lain sangat penting bagi proses pemberian produk dan jasa pelayanan kesehatan bagi pasien. Responden menilai bahwa adanya tenaga kerja bidang K3 tidak meningkatkan pengetahuan mereka tentang K3. Responden mendapatkan pengetahuan tentang K3 dari orang lain di sekitarnya seperti pekerja lain dengan tingkat pengetahuan yang lebih baik tentang K3 maupun responden juga mendapatkan pengetahuan tentang K3 melalui berita di internet. K3 di rumah sakit harus dilakukan secara bersama-sama sehingga seluruh pekerja diharapkan ikut aktif dalam penyelenggaraan K3. Tidak hanya bersumber dari tenaga K3, seluruh pekerja diharapkan mempunyai pengetahuan K3yang setidaknya cukup baik yang bersumber dari berbagai pihak.

MenurutKMK1087/MENKES/SK/VIII/2010 Program Keselamatan dan Kesehatan Kerja yang harus diterapkan yaitu pengembangan kebijakan K3RS, pembudayaan perilaku K3RS, pengembangan SDM K3RS, pengembangan pedoman, petunjuk teknis dan Standard Operational Procedure (SOP) K3RS, pemantauan dan evaluasi kesehatan lingkungan tempat kerja, pelayanan kesehatan kerja, pelayanan keselamatan kerja, pengembangan program pemeliharaan pengelolaan limbah padat, cair, dan gas, pengelolaan jasa, bahan beracun berbahaya dan barang berbahaya, dan pengembangan manajemen tanggap darurat.

Berdasarkan Keputusan Menteri Kesehatan No 1087 Tahun 2010 tentang Standar Keselamatan dan Kesehatan Kerja yaitu pemeriksaan berkala meliputi pemeriksaan fisik lengkap, kesegaran jasmani, rontgen paru-paru (bilamana mungkin) dan laboratorium rutin, serta pemeriksaan-pemeriksaan lain yang dianggap perlu dan pemeriksaan kesehatan berkala bagi SDM Rumah Sakit sekurang-kurangnya 1 tahun.

\section{Pembahasan}

Menurut keputusan Menteri Kesehatan Republik Indonesia No.432/MENKES/SK/IV/2007 Tentang Pedoman Kesehatan dan Keselamatan Kerja di Rumah Sakit, komitmen diwujudkan dalam bentuk kebijakan (policy) tertulis, jelas dan mudah dimengerti serta diketahui oleh seluruh karyawan Rumah Sakit.

Kebijakan K3 dibuat secara terlulis, tertanggal, ditandatangani oleh pengusaha atau pengurus RS, secara jelas menyatakan tujuan dan sasaran K3 serta komitmen terhadap peningkatan K3. Kebijakan K3 menjadi landasan utama yang diharapkan mampu menggerakkan semua elemen didalam perusahaan sehingga dapat terwujudnya program $\mathrm{K} 3$ dan program tersebut dapat dilaksanakan dengan baik. Pada RS Prima Medika belum terdapat 
kebijakan yang khusus untuk K3 sehingga belum ada sosialisasi mengenai kebijakan tentang K3 karena RS lagi fokus mengenai penetapan kelas. Komunikasi ini dilakukan agar seluruh karyawan dan pihak yang terlibat di RS mengetahui komitmen RS untuk menerapkan K3RS sehingga dapat terintergrasinya SMK3 didalam melaksanakan semua pekerjaannya. Hal ini tidak sejalan dengan penelitian Izzatul Milla Amiri yang menyebutkan bahwa RS sudah mempunyai ketentuan tertulis tentang K3 yang dibuktikan dengan adanya kebijakan Direktur RS.

Pelaksanaan Keselamatan dan Kesehatan Kerja (K3) adalah salah satu bentuk upaya untuk menciptakan tempat kerja yang aman, sehat, bebas dari pencemaran lingkungan, sehingga dapat mengurangi dan bebas dari kecelakaan kerja dan penyakit akibat kerja yang pada akhirnya dapat meningkatkan efisiensi dan produktivitas kerja

Rumah sakit merupakan salah satu mata rantai didalam pemberian pelayanan kesehatan serta suatu organisasi dengan sistem terbuka dan selalu berinteraksi dengan lingkungannya untuk mencapai suatu keseimbangan yang dinamis mempunyai fungsi utama melayani masyarakat yang membutuhkan pelayanan kesehatan serta sebagai tempat penelitian berdasarkan surat keputusan.

Dalam pemberian pelayanan kesehatan yang optimal di rumah sakit diperlukan sumber daya yang berkualitas. Dengan menggunakan sumber daya yang ada diharapkan rumah sakit dapat menghasilkan suatu output yang maksimal berupa jasa untuk meningkatkan mutu pelayanan. Untuk masalah- masalah tersebut haruslah disadari bahwa keberhasilan rumah sakit antara lain disebabkan sumber daya manusia, sehingga sumber daya manusia dipandang sebagai asset rumah sakit, bahkan merupakan investasi rumah sakit, apabila tenaga tersebut merupakan tenaga yang terampil. Keberhasilan pelayanan di rumah sakit tidak terlepas dari berbagai faktor pelayanan keperawatan yang biasa disebut dengan asuhan keperawatan.

Seorang perawat dalam melaksanakan manajemen K3 harus memiliki sikap yang sesuai dengan nilai-nilai kesehatan dimana seluruh nilai positif yang ada dalam dirinya menjadi pendorong perilaku sehat dan menjadi upaya dalam meningkatkan kesehatan dan keselamatan selama bekerja. (Riska, 2017)

Kesehatan dan keselamatan kerja merupakan salah satu isu penting di dunia kerja saat ini. Kesehatan kerja merupakan suatu kondisi yang bebas dari gangguan secara fisik dan 
psikis yang disebabkan oleh lingkungan kerja. Risiko kesehatan dapat terjadi karena adanya faktor-faktor dalam lingkungan kerja yang bekerja melebihi periode waktu yang ditentukan dan lingkungan yang menimbulkan stress atau gangguan fisik. Risiko keselamatan dapat terjadi karena aspek-aspek dari lingkungan kerja yang dapat menyebabkan kebakaran, sengatan aliran listrik, terpotong, luka memar, keseleo, patah tulang, serta kerusakan anggota tubuh, penglihatan dan pendengaran.

Keselamatan kerja adalah keselamatan yang berhubungan dengan aktivitas kerja manusia baik pada industri manufaktur, yang melibatkan mesin, peralatan, penanganan material, pesawat uap, bejana bertekanan, alat kerja, bahan dan proses pengolahannya, landasan tempat kerja dan lingkungannya serta cara-cara melakukan pekerjaan, maupun industri jasa, yang melibatkan peralatan berteknologi canggih, seperti lift, eskalator, peralatan pembersih gedung, sarana transportasi, dan lain-lain.

Kecelakaan kerja menjadi salah satu masalah urgen di lingkungan rumah sakit. Hal ini diakibatkan karena rumah sakit merupakan suatu unit pelayanan kesehatan yang memberikan pelayanan pada semua bidang dan jenis penyakit. Oleh sebab itu rumah sakit dituntut untuk dapat menyediakan dan menerapkan suatu upaya agar semua sumber daya manusia yang ada di rumah sakit dapat terlindungi, baik dari penyakit maupun kecelakaan akibat kerja.

Setiap Rumah Sakit wajib melaksanakan pelayanan kesehatan dan keselamatan kerja sesuai yang tercantum pada pasal 23 dalam Undang-Undang No. 36 tahun tahun 2009 tentang kesehatan dan Peraturan Menteri Tenaga Kerja dan Transmigrasi RI No.03/MEN/1982 tentang pelayanan kesehatan kerja.

Dalam Keputusan Menteri Kesehatan Nomor: 1087/MENKES/VIII/2010 tentang standar keselamatan dan kesehatan kerja Rumah Sakit dijelaskan bahwa Rumah Sakit harus menyusun rencana tanggap darurat, membentuk tim kewaspadaan bencana, pelatihan dan uji coba kesiapan petugas, menyiapkan sarana dan prasarana tanggap darurat, membuat kebijakan dan prosedur ketanggap daruratan, upaya pencegahan dan pengendalian, menyediakan jalur evakuasi, melakukan sosialisasi dan penyuluhan, memiliki sistem komunikasi secara internal dan eksternal, serta melakukan evaluasi.

Dalam rangka mewujudkan penyelenggaraan keselamatan dan kesehatan kerja rumah sakit (K3RS) yang lebih efektif, efisien, terpadu (integrated)dan berkesinambungan, maka diperlukan suatu penyelenggaraan sistem manajemen keselamatan dan kesehatan kerja rumah 
sakit (SMK3RS), di mana kelancaran dari implementasi sistem manajemen k3 RS ini sangat diperlukan oleh rumah sakit dalam rangka mensukseskan akreditasi Rumah sakit tersebut.

Sistem manajemen K3RS merupakan bagian dari sistem manajemen rumah sakit secara keseluruhan dalam rangka pengendalian risiko yang berkaitan dengan kegiatan kerja guna terciptanya rumah sakit yang sehat, aman dan nyaman bagi pekerja rumah sakit, pasien, pengunjung atau pengantar orang sakit maupun bagi masyarakat dan lingkungan di sekitar rumah sakit. Sistem manajemen keselamatan dan kesehatan kerja ini meliputi pemberdayaan sumber daya yang ada di rumah sakit, pengembangan sistem manajemen k3rs di rumah sakit yang terdiri atas penetapan kebijakan, perencanaan, pelaksanaan pemantauan dan evaluasi, tinjauan manajemen dan perbaikan yang berkelanjutan.

Berdasarkan Keputusan Menteri Kesehatan No 1087 Tahun 2010 tentang Standar Keselamatan dan Kesehatan Kerja yaitu pemeriksaan berkala meliputi pemeriksaan fisik lengkap, kesegaran jasmani, rontgen paru-paru (bilamana mungkin) dan laboratorium rutin, serta pemeriksaan-pemeriksaan lain yang dianggap perlu dan pemeriksaan kesehatan berkala bagi SDM Rumah Sakit sekurang-kurangnya 1 tahun.

Keselamatan dan kesehatan kerja (K3) bagi para pekerja di Rumah Sakit dan fasilitas medis lain tidak kalah pentingnya dibandingkan dengan sektor industri lainnya. Disadari atau tidak, di lingkungan RS terdapat banyak bahan, alat dan proses kerja yang berpotensi bahaya. Angka Kecelakaan Akibat Kerja (KAK) di RS juga cukup memprihatinkan. Pada prinsipnya permasalahan tersebut timbul karena lemahnya pihak manajemen dalam menjalankan K3 RS dengan baik dan benar, serta tingkat kesadaran pekerja RS akan K3 yang masih rendah. Di samping itu berbagai masalah K3 kurang mendapat perhatian sebagaimana mestinya.

Agar K3 di RS dapat dilaksanakan dengan baik, maka pihak manajemen RS perlu memahami berbagai hal yang terkait dengan K3. Salah satunya dengan kegiatan pelatihan yang tujuannya menjawab atas berbagai permasalahan yang terkait K3 di RS, tidak hanya dari aspek pengelolaannya saja, akan tetapi lebih meningkatkan profesionalisme SDM K3, sehingga diharapkan para SDM K3tersebut lebih peka dan kreatif dalam implementasi K3 di RS. Dengan penerapan K3 RS yang baik dan benar tersebut maka berbagai PAK dan KAK dapat diminimalisasi, produktivitas pekerja dapat ditingkatkan dan pada akhirnya dapat meningkatkan profit bagi Rumah Sakit. 


\section{Penutup}

Berdasarkan hasil dapat disimpulkan bahwa penerapan perilaku perawat dalam menerapkan manajemen kesehatan dan keselaman kerja, merupakan bentuk upaya untuk menciptakan tempat kerja yang aman, sehat, bebas dari pencemaran lingkungan, sehingga dapat mengurangi dan bebas dari kecelakaan kerja dan penyakit akibat kerja yang pada akhirnya dapat meningkatkan efisiensi dan produktivitas kerja. Kebijakan K3 menjadi landasan utama yang diharapkan mampu menggerakkan semua elemen didalam perusahaan sehingga dapat terwujudnya program K3 dan program tersebut dapat dilaksanakan dengan baik.

\section{Daftar Pustaka}

1. Suhariono. 2019. Pengelolaan keselamatan dan kesehatan kerja (k3) di Rumah Sakit. Uwais inspirasi Indonesia: Jawa Timur

2. Nazirah R, Yuswardi. 2017. Perilaku perawat dalam penerapan manajemen kesehatan dan keselamatan kerja (k3) di Aceh. Idea Nursing Journal Vol. VIII No. 32017

3. Hasibuan R. 2017. Pengaruh kesehatan dan keselamatan kerja, latihan dan kerja tim terhadap kinerja tenaga medis di Rumah Sakit Budi kemuliaan Batam. DIMENSI, VOL. 6, NO. 2

4. Tukatman,dkk. 2015. Analisis keselamatan dan kesehatan kerja perawat dalam penanganan pasien di rumah sakit Benyamin Guluh Kabupaten Kolaka. Jurnal Ners Vol. 10 No. 2

5. Ibrahim H,dkk. 2017. Gambaran penerapan standar manajemen selamatan dan kesehatan kerja rumah sakit di rumah sakit umum di daerah haji Makassar. Volume 9, Nomor 2

6. Simamora, R. H. (2018). Buku ajar keselamatanpasienmelaluitimbangterimapasienberbasiskomunikasiefektif: SBAR. Medan: USUpress.

7. Simamora, R. H. (2019). Buku ajar pelaksanaanidentifikasipasien. Uwais/nspirasi Indonesia.

8. Yunita R A,dkk. 2016. Analisis faktor-faktor kebijakan dalam implementasi program keselamatan dan kesehatan kerja rumah sakit (k3rs) instalasi gawat darurat Rumah Sakit umum daerah kota Semarang. Jurnal kesehatan masyarakat (e-Journal) volume 4 , nomor 2 . 
9. Erniyati N, Ella N. 2017. Faktor-faktor yang berhubungan dengan pelaksanaan penerapan k3 pada jaga kesehatan di RSIA permata sarana Husada periode Februari 2015. Jurnal Akademi Keperawatan Husada Karya Jaya, Volume 3, Nomor 1.

10. Ivana A,dkk. 2014. Analisa komitmen manajemen rumah sakit (RS) terhadap keselamatan dan kesehatan kerja (K3) pada RS Prima Medika Pemalang. Jurnal kesehatan masyarakat (e-Journal) volume 2 , nomor 1.

11. Dolongpaha W V G, dkk. 2019. Gambaran pelaksanaan program kesehatan dan keselamatan kerja rumah sakit (k3rs) di rumah sakit umum daerah Talaud. Jurnal KESMAS, Vol. 8, No. 7.

12. Alayyannur P A. 2018. Korelasi komitmen manajemen pelatihan k3 dengan pengetahuan rumah sakit "X". Journal of Industrial Hygiene and Occupational Health Vol. 2, No. 2. 